\title{
AN ADAPTATION OF BESSEMER PLANT TO THE BASIC PROCESS.
}

\author{
By A. L. Holley, Memb. Inst. Civ. Eng., ete.
}

\section{The Basic Processs.}

The process of dephosphorizing iron in the Bessemer converter, held in this country under patents of Thomas, Snelus and Riley, is called, by common consent, the Basic Process.

In the ordinary Bessemer operation, when the flame "drops," as observed by the naked eye, or when the carbon lines disappear, as more accurately observed through the spectroscope, there still remain in the metal some hundredths of a per cent. of carbon, also of silicon, also all the phosphorus which the metal originally wontained. Further blowing would oxidize the iron itself. But if the slag in the converter, instead of being acid (chiefly silica), as in the ordinary operation, is basic (chiefly lime), a small part of the phosphorus will be found in the slag, instead of in the metal, when the flame drops. And if the blowing is further continued for two or three minutes, all the phosphorus, excepting a few hundredths, will be found in the slay, and the iron will not have been much oxidized; it will have been protected by the phosphorus. Chemists disagree as to the precise reactions which occur; we suppose that phosphorus is always oxidized by the air blast, and that it constantly returns to the iron, in presence of an acid slag; we know that a basic slag retains the phosphorus, however it may have got it.

The basic process, therefore, consists of two things: First, the maintenance of a basic slag; second, the "afterblow."

First. The basic slag is formed by the addition of about twenty per cent. of lime to the iron charge in the converter before or during the blowing. The basic slag is maintained chiefly by making the converter lining of lime, and also by using iron low in silicon. An acid lining would be destroyed by the lime additions, and would vitiate the slag. The latter result would be produced also by silica formed by the oxidation of the silicon in the iron. The grand difficulty has been the limited durability of the lasic lining. After much costly experimenting, practicable linings have been made of dolomite bricks 
- bricks formed by wetting and moulding pulverized magnesian limestone and then burned at the highest attainable temperature. The magnesia prevents the bricks from crumbling when exposed to the air. Linings are also formed by ramming hard-burned, pulverized dolomite, mixed with ten per cent. of tar, into the converter. Ordinary fire-brick tuyeres are used in lime bottoms, or the bottoms are rammed around rods which form tuyere-holes.

Second. The afterblow presents little difficulty; its duration is soon determined for any grade of material and products.

In order that the phosphorus may be thoroughly removed-it seens rather paradoxical to say-there must be plenty of it. Silicon, the chief heat-giver in the ordinary process, must, as we have seen, be kept low. Phosphorus is also a heat-giver, but there nust be enongh of it to maintain, by its combustion, perfect fluidity in nearly pure iron. At a lower temperature the Bessemer process could not be completed. Iron best adapted to the basic process has two to two and one-half per cent. of phosphorus and under one per cent. of silicon, also one and one-half to two and one-half per cent. of manganese-a heat-giver and a valuable ingredient in steel-but the manganese may be dispensed with at this stage of the operation. The afterblow completely removes silicon and reduces other impurities.

Spiegeleisen, or ferro-manganese, are added to the blown metal, but most of the slag is first poured out of the converter, so that the manganese shall not carry the phosphorus out of the slag to the iron. Otherwise the process is conducted in the usual manner.

In nearly all parts of the United States there are phosphoric ores adapted to the basic process. They are usually cheap, and in some regions, of the South especially, they are so abundant, and so associated with coal and limestone, that the manufacture of cheap steel is likely to become, in such localities, a vast and important industry.

The maintenance of refractory linings in Bessemer converters, in such a way as to promote regular and maximum production, has been the subject of more experimenting than any other feature of the Bessemer system, and it is still the least perfect and satisfictory feature, excepting perhaps the casting of steel. Linings are not only eroded by the mechanical action of the charge, but they are chemically decomposed by its various slags. The silica linings ustally emploved have, indeed, been so improved that an average of say sixty charges per twenty-four hours can be got out of a pair of converters, and the 
shifting of interchangeable converter bottoms (containing the tuyeres) is so rapid that it does not delay production; but the repairing of the fixed lining just above the tuyeres, where both mechanical and chemical action are most severe, is frequently the cause of delay, and the operation rapidly performed between heats is tedious and costly. The accumulations of slag on other parts of the lining must also be quarried out, else the converter will become too small for the charge,

These are the conditions of maintaining silica linings; but the difficulties are increased, probably about threefold, when the linings are made of lime, for the basic process. The basic process consists in removing phosphorus from the iron under treatment by retaining the phosphorus oxidized by the blast, in a basic slag formed of say twenty per cent. of lime added to the charge. An acid (silica) lining would vitiate the basic slag, and would also be rapidly destroyed by it. Lime containing some magnesia, and produced by burning magnesian limestone (dolomite), is at present the only basic material successfully used for converter linings. It is usually made into bricks, which are hard burned and built up with mortar of similar material to form the lining.

Basic bottoms and tuyeres stand ten to fifteen charges, nearly equaling acid bottoms, and they may be readily changed; but basic linings, near the tuyeres, and also in other parts where abrasion is severe, wear rapidly and must be frequently repaired by cooling the converter and inserting new bricks, or patching in some suitable manner. The converter is thus put out of use for at least twenty-four hours-a very serious delay to production. From a wide observation, the author feels safe in saying that a basic lining is rarely run above sixty charges without extensive repairs, and in some works repairs are made every time a bottom is set. With some irons there is also an accumulation of slag around the mouth of the converter; its removal sometimes also causes further delay.

The output of a pair of converters in Europe averages about half that of a pair of converters of the same size in the United States, and is often less than half. The limited endurance of basic linings in Europe is, therefore, a less conspicuous defect than it is here, where one converter must make 25 or 30 charges in twenty-four hours, so that the repairs of basic linings, as at present conducted, would keep an American plant idle half the time. This delay is really as impor- 
tant in Europe as it is here; the greater the output from a given plant, the cheaper the product.*

In order, therefore, that the basic process may come into extensive use, basic linings must be so maintained that their output will nearly equal that of acid linings.

There are two reasonable conditions of improvement: the one is to prolong the endurance of basic materials, so that their repairs can be made with little delay, while the converter is in position for use. There seems to be little or no progress, or probability of immediate progress in this direction. The other is the rapid and complete removal of a worn lining and the replacement of a repaired one. A third system, seriously proposed, is to double or treble the entire converting plant. The only practicable way to replace a refractory lining (which cannot be handled by itself) is to replace the vessel which contains it. The worn portions of the lining may thus be repaired at leisure, in another part of the works, rather than in position for use, where repairs would retard output.

An obvious way to replace an entire converter lining is to replace the entire converter. This system is alrealy under construction in Europe. The method is also obvious-lifting the converter bodily out of its pillow blocks, and conveying it to the repair shed by means of an overhead traveler; then setting a repaired converter in place by the same means. Such a plant is doubtless cheaper than a duplicate plant, and its output should be materially greater than that of fixed converters. But the operation of changing an entire converter must be slow and tedious. When the arrangement is such that pillow block caps are required, these must be loosened by unscrewing heavy nuts; then they must be made fast to the crane chain, lifted, traversed and set down. The blast pipe connection must be broken, and possibly some platforms must be removed. Then the traveler is placed exactly centrally over the converter, ponderous chains are made fast, the mass is raised high enough to clear surrounding parts, and drawn laterally to the repair shed; then the converter is placed centrally over its seat and lowered and steadied (as it swings from a chain) into its pillow

* The statement sometimes made in England that the rapid production in America impairs quality of product is but a cover for inadequate plant. Steel is obviously no better because five hours instead of one are consumed in setting a vessel bottom, or because it may take twice as long in an English works to handle materials and product. 
blocks. The repaired converter is raised, traversed and set in place by repeating all these operations; the blast connection is then made, and the pillow block caps are lifted, traversed, steadied into place and screwed down. If the converter is removed in sections, transferring each section and making the refractory joints will occupy much more time. The chimneys and the openings in the side of the building must be high enough to make passage not only for the traveler but for the converter when lifted out of its seat, and for the chains that sustain it. A traveler of the required power, height and length is obviously a ponderous and costly structure, and to work with reasonable speed it must have independent steam power-the hydraulic system of the works cannot well reach it.

The method of replacing the lining proposed by the author, and shown in the engravings, is removing only the shell of the converter; lowering it out of the trunnion ring easily and rapidly, by means of a simple lift and car, and replacing a repaired shell by the same means. No pillow block caps, blast comnections, nor other surrounding parts are touched; a dozen cotters are knocked out, the shell is lowered and run straight back to the repair shed, the new shell is rum in, lifted and cottered on; this is all. 'The machinery and transference are on the general level, and not forty feet or more up in the air. The car may be moved by a small reversing engine or by a hydraulic capstan, by means of a wire rope and sheaves suitably arranged. The car runs against a stop, and the lift is perfectly vertical, so that the shell may be put in place by two rapid motions without the delay of adjustment.

The lining may be heated before the shell is put in place, and bottoms (and tuyeres) may be separately removed, as at present, or they may be taken away with the shell and repaired withont removal from it. In the latter case, the shell must be placed in trumnions, in the repair shed, so that the bottom may be turned downward for repairs. But if the bottom is first removed, the shell need not be placed in trumnions in the repair shed; the shell will stand mouth downward on the car, a position most favorable for repairing both the mouth and the lining about the tuyeres, which are the two places chiefly needing repairs. This is doubtless the better plan, and it saves the cost of supplementary trunnion rings and turning gear. The engravings show the converter hung so high above the general level that the bottom and tuyere box can be hauled out, with the shell, under the trunnion ring. In case 
the bottom is previously removed, the converter may be hung some three feet lower.

It has been remarked that in American works converter bottoms are changed so rapidly that one is always ready, even when tuyeres stand but eight or ten operations. Changing converter shells is much more rapid than changing bottoms. The several operations of removal and transportation are the same, but the converter lining must be trimmed out to receive the new bottom, and a refractory joint must be made. The new shell has merely to be cottered on.

The comparative cheapness of apparatus to change the shell, instead of the entire converter, is obvious. The two hydraulic lifts for removing the bottoms are made heavier, and there are several cars of 'simple construction; this is the entire extra apparatus. The increased cost of the converters is not important. In the other case, the traveler with its engine, and the standards and turning gear in the repair shed, and the trunnion rings and pinions (the chief cost of the converters) for each spare shell, approach in expense that of a duplicate plant complete.

But one objection has been raised, as far as the author is aware, to the plan proposed, and that is the possibility of damage to the lift under the converter, in case the charge should burn through and fall upon it. To avoid such damage, the lift table may be sunk several inches below the pit level and covered with sand. It may be remarked that lifts under converters are used in nearly all the American works with satisfactory results.

The engravings illustrate the construction and arrangement so fully that little explanation is required. The trunnion ring (Figs. 1 to 4 ) is of cast iron, with an inch wrought iron lining; or it may better be a steel casting, which will not require a lining. There is a two-inch annular space between the trunnion ring and the converter shell, and the shell is prevented from shifting laterally by means of the wedges shown in Fig. 1. The car is raised by the lift to receive the shell; or the shell may be lowered by means of a fork on the lift passing through the car.

This construction of converters has led the way to a general improvement in the design of the plant. The shells and bottoms may be run out laterally into the converting house, but the space here is insufficient for convenient repairs, and the shells for one converter could not be well got to the other. In order that there may be one 
common place for repairs, and ample room both for spare shells and spare bottoms, they must be run out in rear of the converters, as shown in Fig. 8. If blast furmace metal is brought directly to the converters this rear space is not otherwise wanted; but if cupolas are placed there, as is usually the case, they must be so arranged that the shells can pass out under them.

But the cupolas (excepting the spiegel cupolas) may best be placed elsewhere; if there are blast furnaces the cupolas may be so arranged near them as to utilize the same system of transportation, hoisting, blowing and hot blast. There should be plenty of spare gas from good furnaces to heat cupola blast. These are very important considerations, regarding both cost of plant and economy of working; and, judging from the experience at many works, the disadvantages of hauling fluid iron some thousands of feet in a railway ladle are less than those due to crowding the melting department and its stock yard and appurtenances, close behind the converters. Fluid iron is hauled from one to two miles* without chilling; it need usually be hauled but a few hundred feet, and the cost of the transporting plant and service should be about the same for the two systems. There are two important advantages in the arrangement shown by the engravings:

1. Placing only the spiegel cupolas, instead of the entire melting department, close behind the converting house leaves its rear comparatively open to free ventilation, thus cooling not only the space around the converters, but also the casting pit.

2. This arrangement provides ample room for the convenient removal of slag, which, in the basic process, is very voluminous; one long dumping car placed under both the converter and the ladle catches it all, and as the bottom of the pit is on the general level, the slag is neither handled nor lifted; the car is simply hauled out by the yard locomotive and dumped. Experts well know the cost and inconvenience of breaking up and quenching slag in the pit, and of lifting it out of the pit, and then loading and removing it.

Iron may be got to the converters in a ladle by various means. It may be hauled on the general level to one or more hoists, and run into short spouts or directly into the converter mouths, or it may be drawn up a gradual incline or lifted by a hoist to an elevated railway near the converters, and thence tipped or tapped into them directly or

* At the Barrow Works it is hauled two miles; at Ebbw Vale some five miles. 
through spouts. The short elevated railway, as shown in Fig 7 , has one conspicuous advantage-it is out of the way of all other apparatus and operations; it does not cross railways nor interfere with any transportation on the general level. This is an important feature when a charge is made every 20 to 30 minutes. The ladle is drawn by a locomotive to short, steep spouts leading to the converters; there is no lateral or hand movement, and hence no delay. A spout leads to each converter, chiefly for the purpose of leaving the space between the converters (where the common spout is usually placed) quite free for the spiegel ladle.

The spiegel cupolas and their appurtenances occupy so little room that they are placed, without interference with other apparatus, verr near and above the converters. A railway ladle receives the spiegel from either cupola and tips it directly into the converter, quickly and hence completely, by a short run and without hoisting or lateral movement. It may be weighed in transit if desired. The wide platform between the converters is at other times free for bringing lime, scrap or other materials to the converter mouths, and these materials are conveniently raised by the cupola hoist.

The floor of the converting house is raised a few feet, so that the pit bottom may be on the general level, for the convenient removal of slag, as before explained. The ground outside of the converting house slopes gradually to the general level. This facilitates the removal of products and also the drainage.

The plant for repairing shells consists of two turn tables, some short railways and a shed; also some platforms and a lift for materials. If bottoms are to be removed with the shells there must also be mounted trunnion rings and turning gear; also a crane in the shed; but, as before explained, this seems umnecessary. Room is shown for repairing four shells at a time, but the railways may be lengthened to accommodate more. The plant for repairing bottoms consists of short railways and turn tables, a space for ramming bottoms under a shed and the necessary ovens for drying them; also a crane, which sets the bottoms directly on the oven cars. If ordinary tuyeres are used fewer ovens are required; if the bottom is all one tuyere, rammed around rods, it must be burned for two or three days, so that more and hotter ovens are necessary. The repairing department may obviously be arranged in other ways to suit special cases.

The average output of the American plant, having two 6-ton to 7 - 
ton silica lined converters in one pit, is 100,000 tons of ingots per year. It will doubtless appear that the plant under consideration should produce even more, with basic linings, because it has 10-ton converters, and means of keeping one of them in constant repair, so that the converting operations may follow one another without interruption.

Recapitulation.-1. The endurance of basic linings is so small that the ordinary system of repairs would reduce the output of an American plant about one-half.

2 . The only adequate system of repairs, with existing basic refractory materials, is to remove and replace linings bodily by removing and replacing the vessels containing them.

3. Changing converters, trunnions and all requires very costly apparatus, and much labor and time in disconnecting parts and in making the transference.

4. Changing only the shells of converters (leaving the trunnions and their connections undisturbed) requires only cheap and simple apparatus, and the operation may be performed so quickly that basic linings will give the maximum output of acid linings.

5. Leaving the building open in rear of the converters, instead of placing the melting department there, gives good ventilation and ample space for bottoms and shells to be run out for repairs and for slag to. be removed from the pit. The cupolas (excepting the spiegel cupolas) may be placed elsewhere, especially by adjacent blast furnaces; and. melted metal may be transported thousands of feet without difficulty.

6. Placing the pit bottom on the general level allows slag to be hauled away directly, without rehandling or lifting. The elevation of the converting house floor thus produced facilitates the removal of products.

7. The metal ladles are brought in behind and above the converters; and are discharged by separate spouts, so as to leave the space between the converters open for a short run of the spiegel ladle, and of lime and other solid materials to be charged.

8. The spiegel cupolas are placed near and above the converters, so that the metal may be run in quickly and completely, without vertical or lateral movement, by means of a ladle car.

9. The repairing plant is conveniently placed in rear of the converting house, but it may obviously be modified in extent and position, to suit local circumstances. 